\title{
Anatomical Review of Certain Carnations of North Caucasus
}

\author{
E Sh Dudagova, M A Taisumov, H Z Mantaev, M U Elipkhanov, \\ M A-M Astamirova, and E R Baibatyrova \\ Faculty of Natural Sciences, Chechen State Pedagogical University, Grozny, Russia
}

\section{Abstract}

The article provides an anatomical review of 32 species of the genus Dianthus $L$. representatives шт Caucasus, i.e. information about the anatomy of their stem. Most of the studied species have a narrow ecology and are confined to different altitudinal zones. The experience of the introduction of these species in the botanical garden of the Chechen State Pedagogical University of Grozny in the conditions of the steppe climate indicates wide ecological amplitude and potential adaptive capabilities of the species. The main limiting factor in the distribution of these species in natural conditions is probably their low competitiveness. Anatomical signs, apparently, do not have any taxonomic significance. The similarity of the anatomical structure of the

Corresponding Author:

E Sh Dudagova

dudagova@mail.ru

Received: 25 October 2019 Accepted: 15 November 2019 Published: 25 November 2019

Publishing services provided by Knowledge E

(c) E Sh Dudagova et al. This article is distributed under the terms of the Creative Commons Attribution License, which permits unrestricted use and redistribution provided that the original author and source are credited.

Selection and Peer-review under the responsibility of the AgroSMART 2019 Conference Committee.

\section{G OPEN ACCESS} stems of the Caucasus carnations is evident even in species that are well differentiated morphologically. Anatomical differences between them are mainly quantitative. The smallest taxonomic values for the anatomical features of carnations are the radial dimensions of the epidermal cells, the mechanical (sclerenchymal) ring, conducting system. The most significant for these purposes are the morphological features: the size of the calyx and capsule, the shape and degree of dissection of the lobule plate, the shape and size of the chaffs.

Keywords: stem, anatomy structure, parenchyma, chlorenchyma, sclerenchyma, Dianthus L., Caucasus

\section{Introduction}

Preserving the biodiversity of the planet is one of the main problems of modern ecology (Global Strategy of Environment Protection, 2003). This problem includes a comprehensive study of genera, which species are important components of flora, even regional. Unfavorable habitat conditions are significant for the large area of the globe, which causes a variety of plant organisms' adaptations. The adaptation of plant ontogenesis to environmental conditions is the result of their evolutionary development (variability, heredity, selection). 
The identification of adaptation strategies and mechanisms that ensure the preservation and development of plant organisms and communities under the influence of adverse environmental factors is a pressing scientific problem.

Of particular interest in connection with the problem of comprehensive research and the preservation of regional flora is the study of species of the genus Dianthus L. in the flora of Central Ciscaucasia. Species of this genus have an economic, even decorative meaning; they are rather well studied in systematic and other aspects [1-15]. At the same time, the issues of anatomy of this genus are insufficiently studied, there are no links between anatomical and systematic, ecological features of adaptive mechanisms in species of this genus. The problem of establishing the connection between different types of adaptations to the effects of adverse environmental factors in order to determine the adaptive capabilities of species of the genus Dianthus $L$. of the Caucasus flora is relevant.

\section{Methods and Materials}

The work was carried out in 2009--2018 at the Department of Biology and Teaching Methods of Chechen State Pedagogical University (CSPU). For floristic and anatomical studies, a herbaric and fixed in a solution alcohol-glycerin-water (1: 1: 1) material was used. The material was taken from the representatives of the genus Dianthus $L$. from various territories and altitude levels of the placeCaucasus. In total, the study covered 32 types of carnations. Their taxonomic identity was refined according to the "Flora of the Caucasus" by A.A. Grossheim [1] and "Flora of the North Caucasus" by A.I. Galushko [5].

The anatomical structure of the stem was studied on cross sections made with a manual razor in the middle part, a middle internode. A comparative analysis focused on the presence, topography, thickness and ratio of various tissues, the number, size and location of the conducting beams.

An evolutionary-morphological study of individual taxa is an important direction in the study of biological diversity. The family Caryophyllaceae is one of the largest families, it includes about 80 genera and 2.000 species distributed in Eurasia, Africa and America [16--19]. The wide range and diversity of habitat conditions contributed to the formation of peculiar vegetative and reproductive structures in many species. However, there is still no idea about the anatomical evolution of the axial organs of the clove in general, and special studies on the anatomy of most members of the family have not been conducted. 


\section{Results}

1. D. cretaceus Adams. In the stem cross section, the epidermal cells are elongated in the tangential direction, the outer walls of the epidermis are covered with a cuticle.

The radial dimensions of epidermal cells vary within 1.26--1.68 microns, Tangent dimensions vary within 2.1--2.54 microns

The chlorophyll-bearing parenchyma is represented by cells that are somewhat elongated in the radial direction, tightly pressed to each other. The thickness of the chlorophyll-bearing parenchyma varies within 1.26--1.68 microns. The mechanical ring is represented by 3--4 rows of cells of sclerenchymal type with lignified shells. The thickness of the mechanical ring varies in the range of 3.36--2.94 microns. 3--4 rows of thin-walled parenchymal cells adjoin the mechanical ring. The thickness of the parenchymal ring is on average equal to 2.1 microns. Conductive system is of solid type. The phloem ring thickness varies within 2.1--1.26 microns. The wood angios are evenly distributed throughout the ring. The average thickness of the wood ring is 2.1 microns.

The core cells are thin, their cross-sectional shape is hexagonal, ovate-rounded. The core is not fully preserved, a huge intercellular space is formed.

2. D. caucaseus Smith. (D. discolor Smith.). In the stem cross section, the epidermal cells are elongated in the tangential direction, their radial dimensions are on average 1.26 microns, and the tangential ones are 1.68 microns. On top of the outer walls of the epidermis cells are covered with cuticle.

The thickness of the chlorophyll-carrying parenchyma is on average equal to 3.36 microns. The mechanical ring is represented by $4--5$ layers of cells of the sclerenchymal type with lignified shells; its thickness is on average equal to 5.46 microns. 1--2 layers of parenchymal cells with a thin cellulose membrane adjoin the mechanical ring; its thickness is 1.68 microns. Conductive system is of solid type. The thickness of the homogeneous ring of phloem is 1.68 microns. The thickness of the uniform ring of wood varies in the range of 2.1--2.2 microns. The cells of the core are hexagonal, oval. The core is not preserved completely, a huge intercellular space is formed.

3. D. fragrans Adams. The epidermis cells in the stem cross section are elongated in the tangential direction. Their radial dimensions are on average 1.68 microns, the tangential dimensions are 2.94 microns. The thickness of the chlorophyll-carrying parenchyma is on average equal to 2.52 microns. The mechanical ring is represented by 6--7 layers of cells of the sclerenchymal type. The average thickness of the mechanical ring is 9.56 microns. To the mechanical ring 1--2 layers of parenchymal cells adjoins. 
The thickness of the parenchymal ring is on average equal to 2.1 microns. Conductive system is of solid type. The phloem ring thickness is 1.26 microns; the thickness of the one-year wood ring is 3.36 microns. The core is represented by thin-walled cells, the shape of which is quadrangular, rounded; they are closely spaced to each other. An intercellular structure is formed in the core.

4. D. armeria L. The epidermal cells in the cross section are elongated in the tangent direction, their radial dimensions are on average 1.26 microns, tangent dimensions vary from 2.1 to 2.55 microns. The epidermis cells are covered with a cuticle on the outside. The thickness of the chlorophyll-carrying parenchyma is 2.52 microns. The mechanical ring consists of 4--5 layers of cells of the sclerenchymal type, the thickness of which is on average equal to 8.4 microns. Conductive system is of solid type. Phloem ring thickness is 1.26 microns. In the ring of wood there are two plots located against each other, which consist of angios whose diameter varies in the range of 1.26--0.84 microns; the tangent sizes of these sections are on average equal to 29.4 microns, their thickness is equal to 2.94 microns. These areas are interconnected by wood angios, which are evenly spaced, their diameter varies within $0.84-0.42$ microns. The core consists of thinwalled cells, the shape of which is hexagonal, elongated and rounded to the center. The core is not fully preserved; a huge intercellular zone is formed in the center.

5. D. imereticus (Rupr.) Schischk. In the transverse section of the stem, the epidermal cells are elongated in the tangential direction, their radial dimensions vary slightly and are 1.26 microns on average, the tangential dimensions vary within 2.52--2.94 microns. The thickness of the chlorophyll-carrying parenchyma is on average equal to 2.52 microns.

The mechanical ring consists of 2--3 layers of cells of the sclerenchymal type, whose thickness is equal to 2.94 microns. The parenchymal ring, consisting of 2--3 layers of thin-walled cells, the thickness of which is equal to 1.68 microns, adjoins the mechanical ring. The phloem ring thickness varies within 1.68--1.26 microns. In the wood there are two areas where the angios are larger, the thickness of them is 4.2 microns on average, the tangent dimensions are 44.1 microns, which are interconnected by wood angios evenly spaced smaller. The core consists of thin-walled cells, the shape of which is closer to the wood is hexagonal, rounded to the center. Cell size increases in a centripetal direction. The core is preserved completely.

6. D. kubanensis Schischk. In the stem cross section, the epidermal cells are elongated in the tangential direction, their radial dimensions are on average 1.68 microns, tangential dimensions vary between 2.1 and 2.5 microns. The epidermis cells are covered with a cuticle on the outside. The thickness of the chlorophyll-carrying parenchyma 
is on average 4.2 microns. The mechanical ring consists of 5--6 layers of cells of the sclerenchymal type, its thickness is 11.34 microns. Phloem is represented by a one-year ring, the thickness of which is 1.26 microns. In the ring of wood there are two sections, where the diameter of the angios varies within 1.26--2.52 microns. And arranged in 3--4 layers. These areas are interconnected by angios, the diameter of which varies in the range of 1.26--0.84 microns, and they are evenly spaced. The cells of the pith are thin-walled, their shape is hexagonal closer to the wood, and rounded near the center. The core is not fully preserved. The intercellular structure is formed.

7. D. pallens Sibth. \& Sm. (D. lanceolatus Stev. Ex Reichb.). Epidermal cells in the cross section are elongated in the tangential direction, their radial dimensions are 1.26 microns, tangential dimensions vary between 2.1 and 2.94 microns. The thickness of the chlorophyll-carrying parenchyma is on average 2.1 microns. The mechanical ring is represented by $4--5$ layers of sclerenchymal cells, its thickness is 4.2 microns. 2--3 layers of parenchymal cells adjoin the mechanical ring; the thickness of the parenchymal ring is on average equal to 2.94 microns Phloem is represented by a homogeneous ring, the thickness of which is on average equal to 0.84 microns. In the ring of wood there are two plots consisting of 2--3 layers of angios, the sizes of which vary within 1.26--1.68 microns, The tangent sizes of these sections are on average equal to 71.4 microns These areas are interconnected evenly spaced angios, the diameter of which is smaller and varies in the range of 0.84--0.42 microns. The angios are located in 1--2 layers. The core is represented by thin-walled cells, which are hexagonal closer to the wood, round to the center. The core is preserved completely.

8. D. pseudarmeria Bieb. In the stem cross-section, the epidermal cells are elongated in the tangential direction, their radial dimensions vary within 1.2--1.6 microns, and the tangential dimensions -- 2.1--2.5 microns. The outer walls of the epidermis are covered with a cuticle. The thickness of the chlorophyll-carrying parenchyma is 2.4 microns.

The mechanical ring is represented by $4--5$ layers of cells of the sclerenchymal type; its thickness is 2.1 microns.

3-4 layers of thin-walled parenchymal cells adhere to the mechanical ring. In cross section, parenchymal cells have a hexagonal shape. The thickness of the parenchymal ring is 4.8 microns Conductive system is of solid type. Phloem ring thickness varies between 1.2--0.8 microns. In the ring of wood there are two sections that consist of large angios and whose thickness varies within 3.2--2 microns. These areas are connected by half rings of wood, which consist of angios of smaller sizes, their thickness is equal to 0.8 microns. The core cells are thin-walled, densely arranged, their shape is hexagonal closer to the wood, in the center -- rounded, oblong. The core is preserved completely. 
9. D. daghestanicus Charadze. In the cross section of the epidermal cells are elongated in the tangential direction, their sizes are on average equal: radial -- 1.26 microns, Tangential -- 2.94 microns The outer walls of the epidermis are covered with a cuticle. The thickness of the chlorophyll-carrying parenchyma is 2.52 microns. The ring of mechanical tissue consists of 5--6 layers of sclerenchymal cells, the thickness of which is on average equal to 7.56 microns. One layer of thin-walled parenchymal cells adjoins the mechanical ring. The thickness of the ring of bast is on average 1.68 microns.

The ring of wood consists of 4 separate sections, the tangential dimensions vary within 54.6--25.2 microns, their thickness varies within 2.94--2.1 microns The wood cells in cross section are hexagonal and rounded in shape. A core cavity forms in the core.

10. D. ruprechtii Schischk. In the stem cross section, the epidermal cells are elongated in the tangential direction, their radial dimensions vary slightly and on average equal to 1.68 microns, the tangential dimensions vary from 2.1 to 2.5 .5 microns. The thickness of the chlorophyll-carrying parenchyma is 5.4 microns. Mechanical tissue consists of 4--5 layers of sclerenchyma cells, its thickness is 4.2 microns. The thickness of the ring of bast is on average 1.26 microns. The ring of wood consists of 4 separate sections, the sections having the same dimensions are located opposite about each other, two of them have tangental dimensions equal to 50.4 microns, their thickness is equal to 3.36 microns, others -- tangential dimensions are 29.4 microns, their thickness is equal to 2.94 microns

The diameter of the angios varies in the range of 0.84--1.68 microns The core consists of thin-walled densely located cells, the shape of which is hexagonal, rounded. In the middle of a small intercellar space.

\section{Conclusion}

Thus, on the basis of comparatively anatomical studies of the stems of the carnation genus (Dianthus L.) of the Caucasus from various habitats, the influence of environmental factors on the anatomical structure and the systematic significance of the anatomical features were revealed. It is established that the majority of the studied species differ among themselves in quantitative and anatomic parameters. much less often with qualitative signs, preserving the general plan of the anatomical structure of the stems.

The complex of meso- and xeromorphic anatomical features of the genus representatives was determined. The manifestation of the degree of xeromorphic structure of the 
stem depends on the ecological conditions of growth of the species: the xeromorphism of the anatomical features of the stem increases as the conditions of habitat aridize.

\section{References}

[1] Grossheim, A.A. (1939--1967). Flora of the Caucasus, 2rd. ed., vol. 1--7. Baku; Leningrad.

[2] Grossheim, A.A. 1930. Essay on the vegetative cover of the Transcaucasus Tiflis: Transcaucasian. experimental research instit. waterworks, 38 p.

[3] Kharadze, A.L. (1960). Endemic hemixerophilic element of high mountains of the Greater Caucasus. Botanical Issues: Materials on the study of flora and vegetation of high mountains, vol. 5. Moscow; Leningrad: Publishing House of the Academy of Sciences of the USSR, pp. 115--126.

[4] Galushko, A.I. (1965). New species of the genus Dianthus L. New. syst higher height. Moscow; Leningrad: Science, pp. 118--120.

[5] Galushko, A.I. (1978). Flora of the North Caucasus, vol. 1. Rostov on Don: Publishing House of RSU, $317 \mathrm{p}$.

[6] Galushko, A.I. The third meeting on issues of studying the plants of high mountain areas. The results of the introduction of high-mountain plants in the botanical garden of Kabardino-Balkarian University. (Report. 1965, 1980).

[7] Kuzmina, M.L. (1996). New species, combinations and finds of the genus Dianthus (Caryophyllaceae) in the Caucasus. Botanical Journal, vol. 81, no. 8. pp. 79--82.

[8] Taysumov, M.A., Teymurov, A.A. (1998). Comparative-anatomical analysis of the stems of some species of Dianthus L. Proceedings Peace, accordance and cooperation, dedicated to the 60th anniversary of ChSU of Grozny, pp. 64--65.

[9] Taysumov, M.A. (2009). Systematics and geography of the subfamily Caryophyllodeae Juss. North Caucasus. PhD dissertation thesis, Astrakhan, 50 p.

[10] Shulkina, T.V. (1970). Biology of some herbaceous introductions in Leningrad, In the book: Plant Introduction and Green Building, iss. 10, pp. 131--161.

[11] Skipina, K.P. (1973). Morphogenesis shoots of cloves reparative in a closed ground. Byul. The main botanical garden, iss. 89, pp. 60--64.

[12] Gogitashvili, E.V., Mikeladze, P.M. (1985). Comparative histochemical study of a number of bioactive compounds of species of the genus Dianthus L., growing in Georgia. Introduction of plants and green building, vol. 16, pp. 124--134. 
[13] Vasineva, L.I. (1990). To the question about the polymorphism of Carnation Amur. Modern problems of ecological anatomy of plants: Mater. II All-Union. meetings on ecologist, plant anatomy. Vladivostok: Far Eastern National University, pp. 111--113.

[14] Onozaki, T., Yamaguchi, T., Himeno, M., Ikeda, H. (2001). Evaluation of Wild Dianthus Accessions for Resistance to Bacterial Wilt (Pseudomonas caryophylli). J. Japan. Soc. Hortic. Sc., vol. 68, no. 5, pp. 974--978.

[15] Lu, Zh., You-Ming, C., Quiang, Zh., Hui-Yu, Z., Min-Ren, H. (2002). Sequence of the ITS Region of Nuclear Ribosomal DNA (nr DNA) in Xinjiang Wild Dianthus and its Phylogenetic Relationship. Acta genet, sinica, vol. 29, no. 6, pp. 549--554.

[16] Taysumov, A., Umarov, M.U., Lorsanova, Y.E., Umaeva, A.M. (2004). The system of the genus Dianthus L. of the Caucasus, built on an anatomical basis. Proceedings of the Third Scientific and Practical Conference. Problems of Botany of Southern Siberia and Mongolia. Barnaul, pp. 124--132.

[17] Kostychev, S.P. (1920). The structure and thickening of the stem of dicotyledons. Appendix to the journal of the Russian Botanical Society, iss. 5, pp. 78--86,

[18] Kondratieff-Melville, E.A. 1956. On the structure of the conducting system of the herbaceous dicotyledon stem. Bot. Zh., no. 9, pp. 27--35.

[19] Ivan, Z.E. Anatomical features of some alpine plants of the Central Caucasus. Author's abstract. diss.... Cand. biol. sciences. Ordzhonikidze, 24 p., 1963 